Check for updates

Cite this: RSC Adv., 2017, 7, 33194

\title{
Silibinin protects Staphylococcus aureus from UVC-induced bactericide via enhanced generation of reactive oxygen species
}

\author{
Jia-Yi Cai, ${ }^{a}$ Yuan-Yuan Wang, ${ }^{a}$ Kai Ma, ${ }^{a}$ Yong-Na Hou, ${ }^{a}$ Jian Li, ${ }^{a}$ Guo-Dong Yao, ${ }^{\text {bc }}$ \\ Wei-Wei Liu, ${ }^{a}$ Wuxiyar Otkur, ${ }^{a}$ Toshihiko Hayashi, ${ }^{a}$ Kikuji Itoh, ${ }^{d}$ Shin-ichi Tashiro ${ }^{e}$ \\ and Takashi Ikejima (D) *a
}

Silibinin is a major bioactive component of silymarin extracted from the milk thistle Silybum marianum. Silibinin has therapeutic potential for a wide variety of applications including anticancer, hepatoprotective and antiinflammatory medicines. There are studies reporting that silibinin has shown anti-bacterial effects, but its underlying mechanism has not yet been elucidated. In the present study, UVC inhibited growth of $S$. aurues in a dose-dependent manner and up-regulated production of reactive oxygen species (ROS). Silibinin treatment improved the survival of $S$. aureus in the presence of UVC. Interestingly, silibinin further enhanced the generation of ROS and activities of antioxidant enzymes (catalase (CAT) and glutathione peroxidase (GSH-PX)). To determine the role of ROS induced by silibinin, the scavengers ( $N$-acetylcysteine (NAC), glutathione (GSH) and superoxide dismutase (SOD)) or donors ( $t \mathrm{BHP}$ and $\mathrm{H}_{2} \mathrm{O}_{2}$ ) of ROS were used to treat the bacterial cells. The results showed that ROS scavengers down-regulated the protective effect of silibinin, while ROS donors up-regulated it. Therefore, ROS produced by silibinin protects $S$. aureus cells from UVC-induced cell death. Our findings revealed novel insights into the relationship between silibinin, bacteria and ROS. Elucidation of the relationship will contribute to the development of important applications for further use of natural products, particularly for therapeutic strategies for $S$. aureus-associated diseases.

Received 7th April 2017

Accepted 27th June 2017

DOI: $10.1039 / \mathrm{c} 7 \mathrm{ra03981f}$

rsc.li/rsc-advances unrepaired in hamster cells. ${ }^{7}$ UV is divided into three regions according to spectrum wavelength: UVA $(320-400 \mathrm{~nm})$, UVB $(280-320 \mathrm{~nm})$ and UVC $(200-280 \mathrm{~nm})$. Among them, UVC has the strongest bactericidal effect.

ROS are toxic byproducts of aerobic metabolism. Other stresses such as nutrient limitation and ultraviolet radiation also elicit oxidant responses.8,9 Depending on molecular sensing and efficient signaling to enhance antioxidant defense mechanisms such as eliminating/decomposing ROS or repairing the ROS-caused DNA damage, cell survival and resistance to oxidative stress are enhanced. ${ }^{10-12}$ ROS can interact with RNA, DNA, proteins and lipids. ${ }^{13}$ The cell's repairing machinery such as superoxide dismutases and catalases can regulate endogenously generated ROS and maintain them in normal level. ${ }^{12}$ On other hand, at higher concentrations, ROS could induce oxidative stress that changes the pattern of gene expression, generating more protein indirectly or directly involved in ROS scavenging or in repairing ROS-caused DNA damage. ${ }^{12,14}$

In recent years, it has been proposed that ROS are highly correlated with the cause of bacterial death. ${ }^{13,15}$ Antibiotics (norfloxacin, ampicillin and kanamycin) induce ROS by activating the electron transport chain and kill Escherichia coli (E. coli) by causing destabilization of cell structures ${ }^{16}$ Conversely, recent report declared that ROS enhanced cephalosporin 
resistance in Enterococcus faecalis. ${ }^{\mathbf{1 7}}$ Briefly, ROS have ambivalent effects on bacteria, leading to death or survival, implying that we need further clarification of the mechanisms that ROS affect cell life.

Many natural products and chemicals with a modulating effect on ultraviolet (UV)-induced ROS generation have been well reviewed. ${ }^{18}$ However, there are few reports on the relationship among silibinin, bacteria and ROS. Thus, in this study we investigated bioactive effects of silibinin on UVC-treated $S$. aureus.

In contrast to the effect of silibinin on antibiotics-induced cell death, here we found that silibinin at an optimal concentration showed a cytoprotective effect from UVC-induced cell death. ROS played an important role in this protective effect of silibinin.

\section{Materials and methods}

\section{Bacterial strains and culture conditions}

Staphylococcus aureus JCM2413 ${ }^{\mathrm{T}}$ were cultured overnight on a rotary shaker $(220 \times g)$ in LB (Luria-Bertani)-rich medium $(1 \%$ tryptone, $0.5 \%$ yeast extract and $1 \% \mathrm{NaCl}$ ) at $37{ }^{\circ} \mathrm{C}$. The cells were stored at $4{ }^{\circ} \mathrm{C}$ in LB agar.

\section{Reagents}

Silibinin (99\% purity) was obtained from Jurong Best Medicine Material (Zhenjiang, Jiangsu, China). It was dissolved in dimethylsulfoxide (DMSO) to make a stock solution. $N$-acetylcysteine (NAC), glutathione (GSH), superoxide dismutase (SOD), hydrogen peroxide $\left(\mathrm{H}_{2} \mathrm{O}_{2}\right)$, tert-butylhydroperoxide $(t \mathrm{BHP})$ and $2^{\prime}, 7^{\prime}$-dichlorofluorescein diacetate (DCFDA) were purchased from Sigma Aldrich (St Louis, MO, USA). The kits of CAT and GSH-PX were from Nanjing Jiancheng Bioengineering Institute (Nanjing, Jiangsu, China).

\section{UVC exposure and silibinin treatment}

The bacteria grown to the stationary phase $(24 \mathrm{~h})$ were harvested by centrifugation at $14000 \times g(10 \mathrm{~min})$, followed by resuspension in fresh LB medium. Cell suspensions $0.5 \mathrm{~mL}$ volume were placed in sterile glass Petri dish $45 \mathrm{~mm}$ diameter (ensuring a bacterial monolayer) and exposed to different doses of UVC (135-1080 $\mathrm{J} \mathrm{m}^{-2}$ ) with gentle shacking at room temperature. Then, the cells were cultured at $37{ }^{\circ} \mathrm{C}$ for $12 \mathrm{~h}$. The radiation dose was adjusted by a UVC spectra radiometer (Lin technology Company, Shenzhen, China), with emission of UVC radiation ranging from 230 to $280 \mathrm{~nm}$ with a peak at $254 \mathrm{~nm}$. The cells were irradiated with UVC in the presence or absence of silibinin.

\section{Colony forming unit (CFU) assay}

The survival ratios of $S$. aureus were determined by bacterial colony forming units (CFU). Cells subjected to the indicated treatments were collected, diluted in LB to a density of $10^{9}$, and $200 \mu \mathrm{L}$ aliquots were spread-plated (at least in triplicates) in LB medium solidified with $1.5 \%$ agar. Colonies were counted after incubation at $37{ }^{\circ} \mathrm{C}$ overnight.

\section{Flow cytometry of DCF-DA positive cells}

Intracellular production of ROS was detected using the probe $2^{\prime}, 7^{\prime}$-dichlorofluorescein diacetate (DCFDA). ${ }^{19}$ Cells subjected to the indicated treatments were collected, washed with $10 \mathrm{mM}$ potassium phosphate buffer ( $\mathrm{pH} 7.0)$, adjusted with the probe (final concentration $10 \mu \mathrm{M}$ ), and incubated at $37^{\circ} \mathrm{C}$ for $60 \mathrm{~min}$ in dark. DCFDA-stained cells were analyzed by using a FACScan flow cytometer (Becton Dickinson, Franklin Lakes, NJ, USA).

\section{Enzyme activity assay}

Catalase (CAT) and glutathione peroxidase (GSH-PX) activities were determined with commercial kits according to the manufacturer's instructions. CAT activity was measured spectrophotometrically by monitoring the ratio of decomposition of $\mathrm{H}_{2} \mathrm{O}_{2}$. ${ }^{20}$ One unit of CAT was defined as the amount required to decompose $1 \mu \mathrm{mol}$ of $\mathrm{H}_{2} \mathrm{O}_{2}$ per minute under the assay conditions. The GSH-PX activity was based on the principle that oxidation of glutathione (GSH) was catalyzed by GSH-PX to produce oxidized glutathione (GSSG). Decrease in the concentration of $\mathrm{GSH}$ that reacts with 5,5'-dithiobis(2-nitrobenzoic acid) (DTNB) yielding stable yellow substances with absorbance at $412 \mathrm{~nm}$ is indicative of GSH-PX activity in cells. ${ }^{21}$

\section{Statistical analysis}

All the experiments were conducted at least in triplicates $(n \geq$ $3)$. Data were expressed as the mean \pm standard deviation (SD). One-way repeated analysis of variance (ANOVA) and TukeyKramer multiple-comparison test were used to the determine a statistical significance. GraphPad 7.0 was used for all statistical calculations. A $p$ value of $<0.05$ was considered statistically significant.

\section{Results and discussion}

UVC irradiation reduced cell viability of $S$. aureus dosedependently

After exposure to UVC irradiation, the numbers of $S$. aureus colonies were substantially reduced in a dose-dependent manner (Fig. 1A). CFU analysis also demonstrated statistically significant decreases in the bacterial loads of $S$. aureus after the irradiation (Fig. 1B). These results showed the bactericidal effects of UVC exposure on S. aureus. The biological effects of UV are usually attributed to enhanced production of ROS, which results in oxidative damage to lipids, ${ }^{22}$ proteins $^{23}$ and DNA. ${ }^{24}$ Therefore, we moved to determine the production of ROS by monitoring the fluorescence intensity after DCFH-DA staining. Results showed that UVC increased ROS production to the maximum at $270 \mathrm{~J} \mathrm{~m}^{-2}$ (Fig. 1C).

\section{Silibinin protected $S$. aureus cells from UVC-induced cell death}

Silymarin flavonolignan is a complex mixture of polyphenolic molecules in which silibinin is the major bioactive component. $^{25,26}$ Silibinin and silymarin both showed antibacterial activities. ${ }^{27}$ Silymarin demonstrated antimicrobial activity 
A

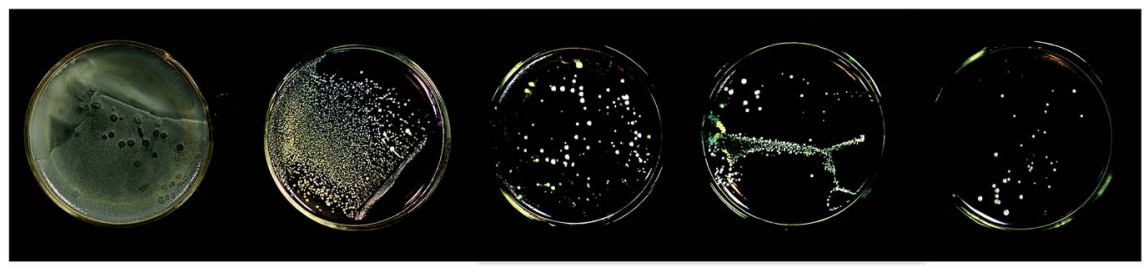

$\operatorname{UVC}\left(\mathbf{J} / \mathbf{m}^{2}\right)$ :

135

270

540

1080

B

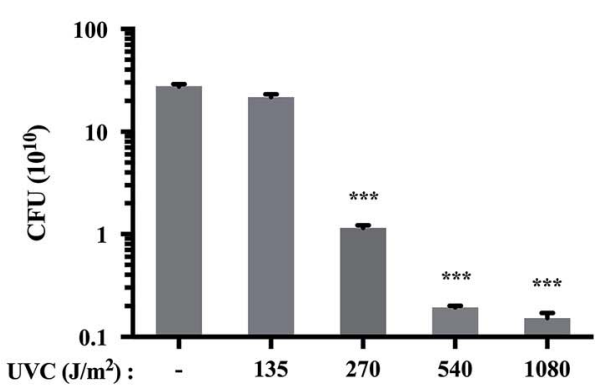

C

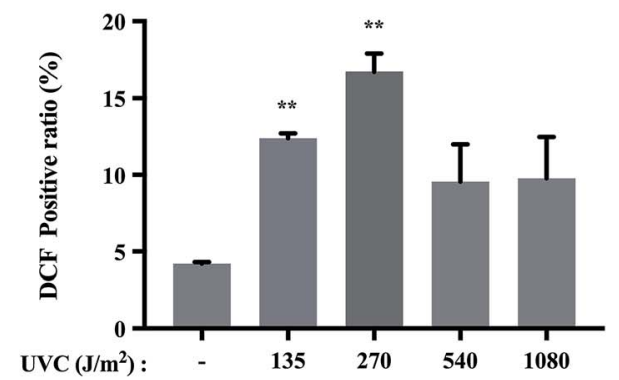

Fig. 1 UVC induced the dose-dependent reduction in the viability of S. aureus cells. (A) Representative images of S. aureus following treatment with different doses of UVC. (B) CFU of S. aureus treated with different doses of UVC irradiation. (C) S. aureus cells were irradiated with different doses of UVC, re-incubated and analyzed for ROS production after $12 \mathrm{~h}$. (**p< $0.01 \mathrm{vs.} \mathrm{control} \mathrm{group).} \mathrm{Date} \mathrm{are} \mathrm{means} \mathrm{value} \pm$ SD from three independent experiments. (***p 0.001 vs. control group).

against Candida albicans with a minimum inhibitory concentration (MIC) of $512 \mu \mathrm{g} \mathrm{mL} \mathrm{m}^{-1}$. Meanwhile, silibinin showed potent bactericidal activity against E. coli with a MIC of 133 $\mu \mathrm{M} .^{27}$ Silibinin inhibited RNA and protein synthesis in Bacillus subtilis and Staphylococcus epidermidis at the concentration of $417 \mu \mathrm{M} .^{3}$

Interestingly, the present investigation provides a new role of silibinin: silibinin blocks UVC-induced $S$. aureus cell death. Silibinin treatment alone on $S$. aureus did not affect cell viability (Fig. 2A and B). However, UVC-induced S. aureus cell death was attenuated to varying degrees by silibinin administration. Silibinin exhibited the maximal effect on cell survival at $25 \mu \mathrm{M}$. At higher concentration $(200 \mu \mathrm{M})$, silibinin did not reverse UVCinduced bactericidal effect (Fig. 2D and E). Silibinin plays a protective role at 25-50 $\mu \mathrm{M}$, while it exerts bactericidal effect at concentrations higher than $100 \mu \mathrm{M} .{ }^{3,27}$ Silibinin possibly possesses bi-directional impacts on both eukaryotic and prokaryotic cells, depending on the concentrations. In human hepatocellular carcinoma cell line HepG2 cells, at a concentration of $200 \mu \mathrm{M}$, silibinin induces DNA lesions, generates oxidized DNA bases and reduces cell viability. However, between 10 and $100 \mu \mathrm{M}$, silibinin was able to reduce the genotoxic effect induced by bleomycin, benzopyrene or aflatoxin $\mathrm{B}_{1}{ }^{28}$

It has been well documented that many polyphenols including silibinin are known to have antioxidant activity, but they can also be turned into oxidants under certain conditions. ${ }^{29}$ For example, silibinin enhances ionizing radiationinduced ROS production under prolonged oxidative stress in
A

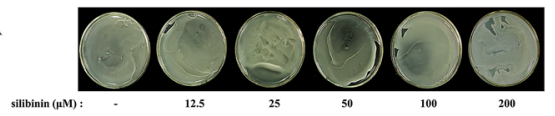

B

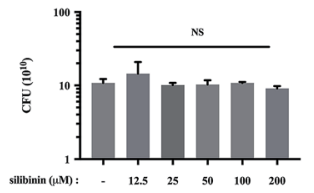

C

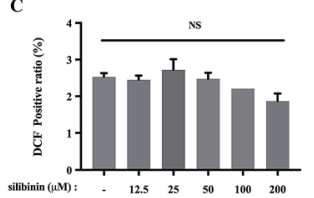

D

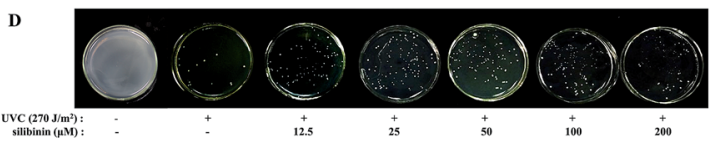

E

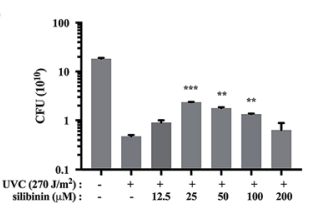

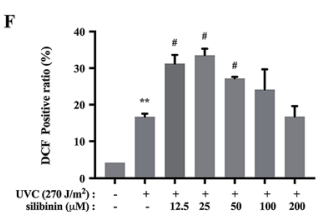

Fig. 2 Silibinin was effective in protecting S. aureus cells forming UVC-induced cell death. (A) Images of S. aureus cultured following silibinin treatment at the indicated concentrations for $12 \mathrm{~h}$. (B) Results of CFU in silibinin-treated S. aureus. (C) Effects of silibinin on ROS generation. (NS: nonsignificant). (D) Representative images of silibinin-treated S. aureus cultured following UVC irradiation. (E) CFU were measured after UVC irradiation in the absence or presence of silibinin. Date are means value \pm SD from three independent experiments. $(* * p<0.01, * * * p<0.001$ vs. UVC-irradiated group). (F) UVC-irradiated $S$. aureus cells were post-treated with silibinin, harvested, and analyzed for ROS production. (** $p<0.01$ vs. control group; \#p $<0.05$ vs. UVC-irradiated group). 
human prostate cancer cells. ${ }^{30-32}$ We examined the effect of silibinin on the ROS production of $S$. aureus, in the absence or presence of UVC. Silibinin did not increase ROS levels in $S$. aureus cells by itself (Fig. 2C), but it significantly enhanced ROS generation in the presence of UVC (Fig. 2F). The ROS production was dependent on silibinin dosage, increasing initially and decreasing later with a maximal enhancement with silibinin at a concentration of $25 \mu \mathrm{M}$. This trend was consistent with the protective efficacy of silibinin on UVC-treated $S$. aureus cells, suggesting a possible relationship between ROS production and cell protection with silibinin treatment.

\section{Scavenging of ROS by NAC, GSH or SOD reduced the protective effect of silibinin on UVC-irradiated $S$. aureus}

Programmed cell death is well established in eukaryotes. It is suggested to exist in bacteria. ${ }^{33-35}$ UVC irradiation, a kind of nonionizing one, can induce oxidative stress, causing eukaryotic apoptosis. ${ }^{36}$ Some results suggested that UVC-induced bacterial cell death was primarily due to ROS-mediated DNA damage. ${ }^{37-39}$ Classically ROS were considered as deleterious agents, contributing to a vast range of damage in eukaryotes or prokaryotes. Consistently, in this study, high concentrations of ROS were deleterious to living cells, leading to cell death. Our results are consistent with the previous research that $E$. coli growth inhibition was caused by a production of ROS by silver nanoparticles. ${ }^{\mathbf{4 0}}$ However, many studies implicate that ROS could function in the process of signal-transduction pathways to regulate transformation and uncontrolled growth potential of tumor cells. ${ }^{\mathbf{4 1 4 2}}$ According to the work by Lubart and co-workers, low amounts of ROS generation could promote bacterial proliferation. ${ }^{43}$

In order to test whether ROS production was involved in the protective effect of silibinin on UVC-induced bacterial cell death, the effects of ROS scavengers were examined. It is known that NAC and GSH reduce endogenous ROS and counteract oxidative stress. $^{44,45}$ GSH contains a thiol group (-SH) which is highly reactive and is the only one substrate of selenium-dependent GSH peroxidase (GSH-PX), ${ }^{46}$ and NAC is a precursor of GSH. ${ }^{47}$ SOD, an antioxidant enzyme, scavenges the excessively generated ROS, superoxide anions in particular, protecting Beauveria bassiana from damage. ${ }^{48}$ Viability of $S$. aureus cells was not affected by the treatment with NAC, GSH or SOD alone, as shown by the CFU assay. However, NAC, GSH and SOD down-regulated the protective effect of silibinin in UVC-irradiated $S$. aureus (Fig. 3A, B, E, F, I and J), suggesting a protective role of the ROS
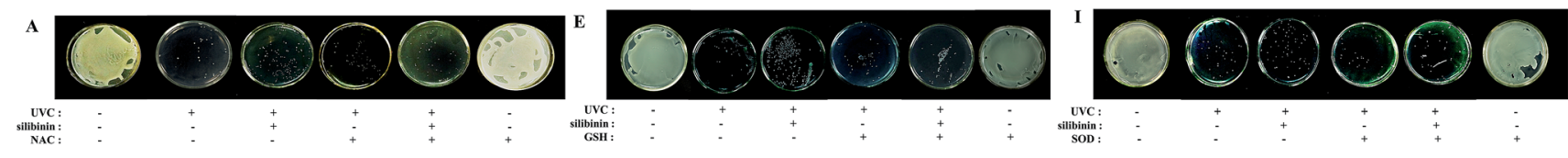

B

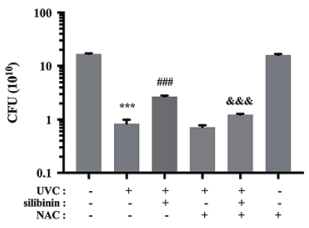

C

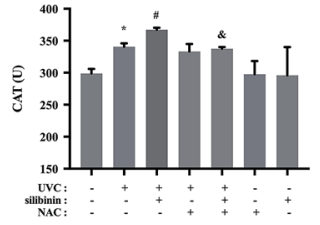

D

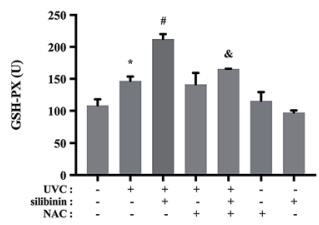

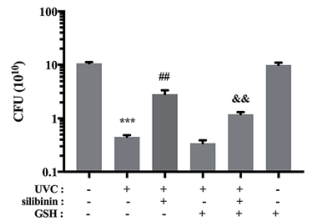

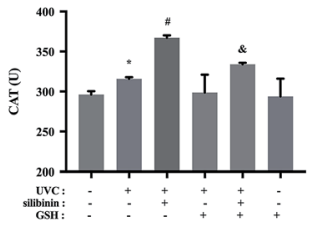

H

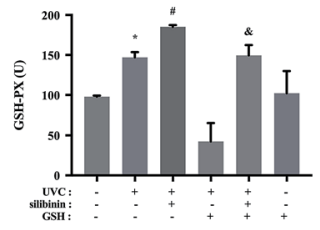

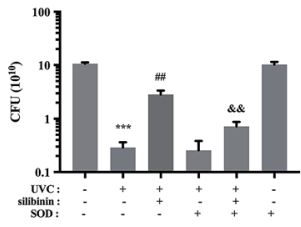

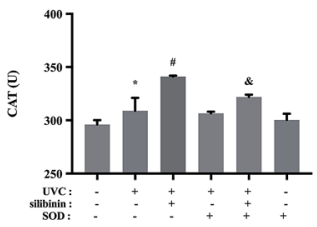

$\mathbf{L}$

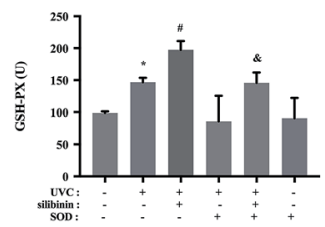

Fig. 3 Scavenging of ROS by NAC, GSH or SOD reduced the protective effect of silibinin on UVC-irradiated S. aureus. In the absence or presence of NAC (8 mM), GSH (10 mM) and SOD $(75 \mathrm{U})$, UVC-irradiated $S$. aureus were treated with silibinin. Images of representative cultures of $S$. aureus

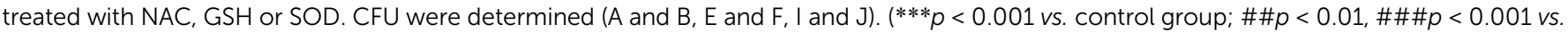
UVC-irradiated group; \&p < 0.05, \&\&p < 0.01, \&\&\&p $<0.001 \mathrm{vs}$. silibinin plus UVC-irradiated group). Changes of the activity of CAT (C, G and K) and GSH-PX (D, H and L) in S. aureus. ( ${ }^{*} p<0.05$ vs. control group; $\# p<0.05$ vs. UVC-irradiated group; \&p $<0.05$ vs. silibinin plus UVC-irradiated group). Date are means \pm SD from three independent experiments. 
A

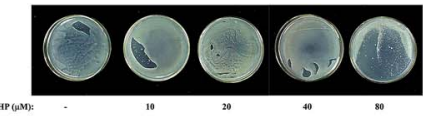

B

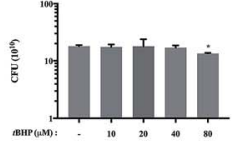

G
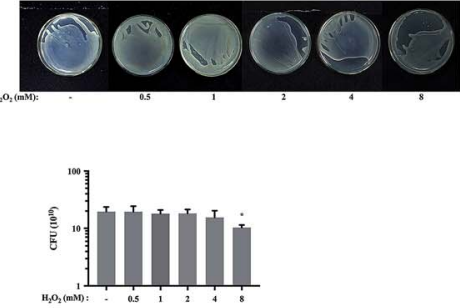

C

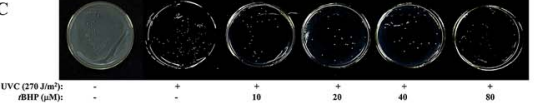

D
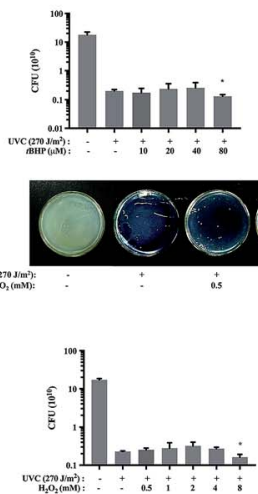

E

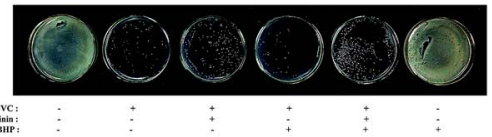

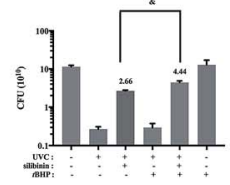

к
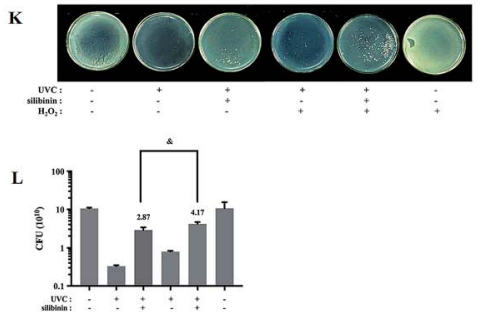

Fig. 4 Silibinin might enhance ROS level, protecting $S$. aureus from UVC irradiation. Images of cultures as follow $S$. aureus were treated with tBHP from 10 to $80 \mu \mathrm{M}$ or $\mathrm{H}_{2} \mathrm{O}_{2}$ from 0.5 to $8 \mathrm{mM}$ were shown ( $\mathrm{A}$ and $\mathrm{G}$ ) and CFU were determined (B and $\mathrm{H}$ ). ( $* 0<0.05 \mathrm{vs}$. control group). (C and I) Representative images of $t \mathrm{BHP}$ - or $\mathrm{H}_{2} \mathrm{O}_{2}$-treated $\mathrm{S}$. aureus cultured, following UVC irradiation. ( $D$ and J) CFU were measured after UVC irradiation with or without of $t \mathrm{BHP}$ or $\mathrm{H}_{2} \mathrm{O}_{2}$. (* $p<0.05$ vs. UVC-irradiated group). In the absence or presence of $\mathrm{H}_{2} \mathrm{O}_{2}$ or $t \mathrm{BHP}, \mathrm{UVC}$-irradiated $\mathrm{S}$. aureus were treated with silibinin. Representative images of cultured $S$. aureus with different treatments. CFU assays were conducted (E, F, K and L). (\&p<0.05 vs. silibinin plus UVC-irradiated group). Date are means \pm SD from three independent experiments.

induced by silibinin treatment. NAC, GSH and SOD repressed the activities of catalase (CAT) and GSH-PX elevated by silibinin treatment, indicating a decreased oxidative stress (Fig. 3C, D, G, $\mathrm{H}, \mathrm{K}$ and $\mathrm{L}$ ). Therefore, we speculated that some kinds of ROS at a localized region in cells or for a time exerted the protective roles in UVC-treated $S$. aureus cell death.

\section{Silibinin might enhance ROS level, protecting $S$. aureus from UVC irradiation}

$t$ BHP is an organic hydroperoxide which has been usually employed to induce oxidative stress in various biological systems. ${ }^{49} \mathrm{H}_{2} \mathrm{O}_{2}$ is one type of ROS. High concentrations of ROS can cause the death of microorganisms. ${ }^{50}$ As Fig. $4 \mathrm{~A}-\mathrm{D}$ and G-J shows that in the absence or presence of UVC irradiation, both $80 \mu \mathrm{M} t \mathrm{BHP}$ and $8 \mathrm{mM} \mathrm{H}_{2} \mathrm{O}_{2}$ significantly reduced $S$. aureus growth ratio. But when the UVC-irradiated bacteria were treated with lower concentrations of $t \mathrm{BHP}(10$ and $40 \mu \mathrm{M})$ or $\mathrm{H}_{2} \mathrm{O}_{2}$ (ranged from 0.5 to $4 \mathrm{mM}$ ), the growth ratio did not significantly change (Fig. 4D and J). Moreover, the growth ratio in $20 \mu \mathrm{M}$ $t$ BHP-treated group $(4.4 \pm 0.4060)$ was significantly higher than that in silibinin alone group $(2.66 \pm 0.1155)$ in UVC-treated $S$. aureus (Fig. $4 \mathrm{E}$ and $\mathrm{F}$ ). Treatment with $1 \mathrm{mM} \mathrm{H}_{2} \mathrm{O}_{2}$ also increased the growth ratio to about 1.5 folds $(4.17 \pm 0.5657)$ of that treated with only silibinin $(2.87 \pm 0.5033)$ in UVC-irradiated $S$. aureus (Fig. $4 \mathrm{~K}$ and $\mathrm{L}$ ). These results suggested that silibinin and $t \mathrm{BHP} / \mathrm{H}_{2} \mathrm{O}_{2}$ have a synergistic protective effect. High levels of ROS induced oxidative stress, leading to bacterial cell death. However, the certain concentration of ROS may play a potentially protective role in $S$. aureus.

UVC irradiation induces the formation of various reactive oxygen species. ${ }^{8,51}$ Low concentration of $\mathrm{H}_{2} \mathrm{O}_{2}$ could play a crucial role in regulation of cell metabolism and cellular signaling in response to environmental stresses such as low- or mediumpressure UV irradiation. ${ }^{52}$ Our results demonstrated that $\mathrm{H}_{2} \mathrm{O}_{2}$ enhanced the protective effect of silibinin on UVC-induced $S$. aureus cell death. We speculated that silibinin protects UVCirradiated bacteria from cell death via enhancing production of some kinds of ROS. But the precise identification of these molecules and their mechanisms requires further investigation.

Mitochondria are evolved from endosymbiotic $\alpha$-proteobacteria belonging to Rickettsia gender. ${ }^{53,54}$ They still present many similarities to prokaryotic cells such as a double membrane, and the ability to produce ATP through the generation of a proton gradient generated across the inner membrane..$^{53,54}$ As toxic byproducts of aerobic metabolism, ROS are primarily formed in mitochondria and peroxisomes, but also at any other cellular compartments. They are then removed or detoxified by an array of antioxidative enzymes such as CAT and SOD, and antioxidants. Many antioxidative systems of the cells, therefore, keep ROS at a basal non-toxic level. ${ }^{55}$ In eukaryotes, mitochondrial oxidative stress leads to cell death, as 5-aminolevulinic acid enhances ionizing irradiation-induced mitochondrial oxidative stress and leads to increased glioma cell death accompanying changes of mitochondrial morphology. ${ }^{56}$ However, mitochondrial oxidative stress also activates cell survival signaling. ${ }^{57}$ Silibinin induces excess mitochondrial ROS production, resulting in increased survival of human melanoma A375-S2 cells. ${ }^{58}$ The effect of ROS in bacteria and mitochondria might potentially share some similar regulation mechanisms through ROS.

\section{Conclusions}

Oxidative stress has been implicated as one of the mechanisms whereby UVC kills bacteria. The formation of ROS may play 
distinct roles in bacteria killing and survival. The present study provides new facts that silibinin-induced ROS are beneficial to the survival of $S$. aureus under UVC-irradiated conditions. The study uncovers novel insights into the relationships between silibinin and bacteria, which has important implications for the usage of natural products in development of therapeutic strategies for $S$. aureus.

\section{Acknowledgements}

This research was supported by National Natural Science Foundation of China (No. 81273517).

\section{References}

1 E. S. Hackett, D. C. Twedt and D. L. Gustafson, Milk thistle and its derivative compounds: a review of opportunities for treatment of liver disease, J. Vet. Intern. Med., 2013, 27, 10-16.

2 I. Anestopoulos, A. Kavo, I. Tentes, A. Kortsaris, M. Panayiotidis, A. Lazou and A. Pappa, Silibinin protects H9c2 cardiac cells from oxidative stress and inhibits phenylephrine-induced hypertrophy: potential mechanisms, J. Nutr. Biochem., 2013, 24, 586-594.

3 D. G. Lee, H. K. Kim, Y. Park, S. C. Park, E. R. Woo, H. G. Jeong and K. S. Hahm, Gram-positive bacteria specific properties of silybin derived from Silybum marianum, Arch. Pharmacal Res., 2003, 26, 597-600.

4 H. K. Kang, H. Y. Kim and J. D. Cha, Synergistic effects between silibinin and antibiotics on methicillin-resistant Staphylococcus aureus isolated from clinical specimens, Biotechnol. J., 2011, 6, 1397-1408.

5 J. L. Ravanat, T. Douki and J. Cadet, Direct and indirect effects of UV radiation on DNA and its components, $J$. Photochem. Photobiol., B, 2001, 63, 88-102.

6 R. P. Gallagher and T. K. Lee, Adverse effects of ultraviolet radiation: a brief review, Prog. Biophys. Mol. Biol., 2006, 92, 119-131.

7 L. Proietti De Santis, C. L. Garcia, A. S. Balajee, P. Latini, P. Pichierri, O. Nikaido, M. Stefanini and F. Palitti, Transcription coupled repair efficiency determines the cell cycle progression and apoptosis after UV exposure in hamster cells, DNA Repair, 2002, 1, 209-223.

8 A. L. Santos, V. Oliveira, I. Baptista, I. Henriques, N. C. Gomes, A. Almeida, A. Correia and A. Cunha, Wavelength dependence of biological damage induced by UV radiation on bacteria, Arch. Microbiol., 2013, 195, 63-74.

9 M. Khakimova, H. G. Ahlgren, J. J. Harrison, A. M. English and D. Nguyen, The stringent response controls catalases in Pseudomonas aeruginosa and is required for hydrogen peroxide and antibiotic tolerance, J. Bacteriol., 2013, 195, 2011-2020.

10 A. Ikner and K. Shiozaki, Yeast signaling pathways in the oxidative stress response, Mutat. Res., 2005, 569, 13-27.

11 R. X. Santos, S. C. Melo, J. C. Cascardo, M. Brendel and C. Pungartnik, Carbon source-dependent variation of acquired mutagen resistance of Moniliophthora perniciosa: similarities in natural and artificial systems, Fungal Genet. Biol., 2008, 45, 851-860.

12 A. Boveris, Biochemistry of free radicals: from electrons to tissues, Medicina, 1998, 58, 350-356.

13 B. Ezraty, A. Gennaris, F. Barras and J. F. Collet, Oxidative stress, protein damage and repair in bacteria, Nat. Rev. Microbiol., 2017, 15(7), 385-396.

14 D. Slade and M. Radman, Oxidative stress resistance in Deinococcus radiodurans, Microbiol. Mol. Biol. Rev., 2011, 75, 133-191.

15 D. J. Dwyer, M. A. Kohanski and J. J. Collins, Role of reactive oxygen species in antibiotic action and resistance, Curr. Opin. Microbiol., 2009, 12, 482-489.

16 M. A. Kohanski, D. J. Dwyer, B. Hayete, C. A. Lawrence and J. J. Collins, A common mechanism of cellular death induced by bactericidal antibiotics, Cell, 2007, 130, 797-810.

17 D. Djoric and C. J. Kristich, Oxidative stress enhances cephalosporin resistance of Enterococcus faecalis through activation of a two-component signaling system, Antimicrob. Agents Chemother., 2015, 59, 159-169.

18 A. A. Farooqi, R. N. Li, H. W. Huang, M. Ismail, S. S. Yuan, H. M. Wang, J. R. Liu, J. Y. Tang and H. W. Chang, Natural Products Mediated Regulation of Oxidative Stress and DNA Damage in Ultraviolet Exposed Skin Cells, Curr. Pharm. Biotechnol., 2015, 16, 1078-1084.

19 J. M. Perez, I. L. Calderon, F. A. Arenas, D. E. Fuentes, G. A. Pradenas, E. L. Fuentes, J. M. Sandoval, M. E. Castro, A. O. Elias and C. C. Vasquez, Bacterial toxicity of potassium tellurite: unveiling an ancient enigma, PLOS One, 2007, 2, e211.

20 R. F. Beers Jr and I. W. Sizer, A spectrophotometric method for measuring the breakdown of hydrogen peroxide by catalase, J. Biol. Chem., 1952, 195, 133-140.

21 K. Ngamchuea, C. Batchelor-McAuley and R. G. Compton, The Copper(II)-Catalyzed Oxidation of Glutathione, Chemistry, 2016, 22, 15937-15944.

22 J. Chamberlain and S. H. Moss, Lipid peroxidation and other membrane damage produced in Escherichia coli K1060 by near-UV radiation and deuterium oxide, Photochem. Photobiol., 1987, 45, 625-630.

23 R. A. Pizarro and L. V. Orce, Membrane damage and recovery associated with growth delay induced by near-UV radiation in Escherichia coli K-12, Photochem. Photobiol., 1988, 47, 391-397.

24 G. P. Pfeifer, Formation and processing of UV photoproducts: effects of DNA sequence and chromatin environment, Photochem. Photobiol., 1997, 65, 270-283.

$25 \mathrm{~V}$. Kren and D. Walterova, Silybin and silymarin - new effects and applications, Biomedical Papers, 2005, 149, 29-41.

26 A. Tyagi, K. Raina, R. P. Singh, M. Gu, C. Agarwal, G. Harrison, L. M. Glode and R. Agarwal, Chemopreventive effects of silymarin and silibinin on $\mathrm{N}$-butyl- $\mathrm{N}$-(4hydroxybutyl) nitrosamine induced urinary bladder carcinogenesis in male ICR mice, Mol. Cancer Ther., 2007, 6, 3248-3255.

27 D. R. de Oliveira, S. R. Tintino, M. F. Braga, A. A. Boligon, M. L. Athayde, H. D. Coutinho, I. R. de Menezes and 
R. Fachinetto, In vitro antimicrobial and modulatory activity of the natural products silymarin and silibinin, BioMed Res. Int., 2015, 2015, 292797.

28 J. P. Angeli, G. R. Barcelos, J. M. Serpeloni, F. Barbosa Jr, A. Nersesyan and M. S. Mantovani, Evaluation of the genotoxic and anti-genotoxic activities of silybin in human hepatoma cells (HepG2), Mutagenesis, 2010, 25, 223-229.

29 N. Zheng, L. Liu, W. W. Liu, F. Li, T. Hayashi, S. I. Tashiro, S. Onodera and T. Ikejima, Crosstalk of ROS/RNS and autophagy in silibinin-induced apoptosis of MCF-7 human breast cancer cells in vitro, Acta Pharmacol. Sin., 2017, 38, 277-289.

30 S. Bhaumik, R. Anjum, N. Rangaraj, B. V. Pardhasaradhi and A. Khar, Curcumin mediated apoptosis in AK-5 tumor cells involves the production of reactive oxygen intermediates, FEBS Lett., 1999, 456, 311-314.

31 G. Galati, O. Sabzevari, J. X. Wilson and P. J. O'Brien, Prooxidant activity and cellular effects of the phenoxyl radicals of dietary flavonoids and other polyphenolics, Toxicology, 2002, 177, 91-104.

32 D. K. Nambiar, P. Rajamani, G. Deep, A. K. Jain, R. Agarwal and R. P. Singh, Silibinin Preferentially Radiosensitizes Prostate Cancer by Inhibiting DNA Repair Signaling, Mol. Cancer Ther., 2015, 14, 2722-2734.

33 J. C. Ameisen, The origin of programmed cell death, Science, 1996, 272, 1278-1279.

34 J. C. Ameisen, Looking for death at the core of life in the light of evolution, Cell Death Differ., 2004, 11, 4-10.

35 K. Lewis, Programmed death in bacteria, Microbiol. Mol. Biol. Rev., 2000, 64, 503-514.

36 J. P. Blaydes, A. L. Craig, M. Wallace, H. M. Ball, N. J. Traynor, N. K. Gibbs and T. R. Hupp, Synergistic activation of p53-dependent transcription by two cooperating damage recognition pathways, Oncogene, 2000, 19, 3829-3839.

37 A. A. Gomes, A. C. Silva-Junior, E. B. Oliveira, L. M. Asad, N. C. Reis, I. Felzenszwalb, K. Kovary and N. R. Asad, Reactive oxygen species mediate lethality induced by farUV in Escherichia coli cells, Redox Rep., 2005, 10, 91-95.

38 A. Krisko and M. Radman, Protein damage and death by radiation in Escherichia coli and Deinococcus radiodurans, Proc. Natl. Acad. Sci. U. S. A., 2010, 107, 14373-14377.

39 A. C. Silva-Junior, L. M. Asad, I. Felzenszwalb and N. R. Asad, Mutagenicity induced by UVC in Escherichia coli cells: reactive oxygen species involvement, Redox Rep., 2011, 16, 187-192.

40 M. A. Quinteros, V. Cano Aristizabal, P. R. Dalmasso, M. G. Paraje and P. L. Paez, Oxidative stress generation of silver nanoparticles in three bacterial genera and its relationship with the antimicrobial activity, Toxicol. In Vitro, 2016, 36, 216-223.

41 C. Xia, Q. Meng, L. Z. Liu, Y. Rojanasakul, X. R. Wang and B. H. Jiang, Reactive oxygen species regulate angiogenesis and tumor growth through vascular endothelial growth factor, Cancer Res., 2007, 67, 10823-10830.

42 J. E. Klaunig and L. M. Kamendulis, The role of oxidative stress in carcinogenesis, Annu. Rev. Pharmacol. Toxicol., 2004, 44, 239-267.
43 R. Lubart, A. Lipovski, Y. Nitzan and H. Friedmann, A possible mechanism for the bactericidal effect of visible light, Laser Therapy, 2011, 20, 17-22.

44 N. M. Reddy, S. R. Kleeberger, J. H. Bream, P. G. Fallon, T. W. Kensler, M. Yamamoto and S. P. Reddy, Genetic disruption of the Nrf2 compromises cell-cycle progression by impairing GSH-induced redox signaling, Oncogene, 2008, 27, 5821-5832.

45 I. Pocsi, R. A. Prade and M. J. Penninckx, Glutathione, altruistic metabolite in fungi, Adv. Microb. Physiol., 2004, 49, 1-76.

46 L. Flohe, The glutathione peroxidase reaction: molecular basis of the antioxidant function of selenium in mammals, Curr. Top. Cell. Regul., 1985, 27, 473-478.

47 I. Downs, J. Liu, T. Y. Aw, P. A. Adegboyega and M. N. Ajuebor, The ROS scavenger, NAC, regulates hepatic Valpha14iNKT cells signaling during Fas mAb-dependent fulminant liver failure, PLoS One, 2012, 7, e38051.

48 F. Martins, J. A. Pereira and P. Baptista, Oxidative stress response of Beauveria bassiana to Bordeaux mixture and its influence on fungus growth and development, Pest Manage. Sci., 2014, 70, 1220-1227.

49 T. R. Kumar and Muralidhara, Induction of oxidative stress by organic hydroperoxides in testis and epididymal sperm of rats in vivo, J. Androl., 2007, 28, 77-85.

50 P. L. Paez, M. C. Becerra and I. Albesa, Comparison of macromolecular oxidation by reactive oxygen species in three bacterial genera exposed to different antibiotics, Cell Biochem. Biophys., 2011, 61, 467-472.

51 Z. B. Alam, M. Otaki, H. Furumai and S. Ohgaki, Direct and indirect inactivation of Microcystis aeruginosa by UVradiation, Water Res., 2001, 35, 1008-1014.

52 I. Slesak, M. Libik, B. Karpinska, S. Karpinski and Z. Miszalski, The role of hydrogen peroxide in regulation of plant metabolism and cellular signalling in response to environmental stresses, Acta Biochim. Pol., 2007, 54, 39-50.

53 M. J. Pallen, Time to recognise that mitochondria are bacteria?, Trends Microbiol., 2011, 19, 58-64.

54 E. Lobet, J. J. Letesson and T. Arnould, Mitochondria: a target for bacteria, Biochem. Pharmacol., 2015, 94, 173-185.

55 R. Mittler, S. Vanderauwera, M. Gollery and F. Van Breusegem, Reactive oxygen gene network of plants, Trends Plant Sci., 2004, 9, 490-498.

56 K. Ueta, J. Yamamoto, T. Tanaka, Y. Nakano, T. Kitagawa and S. Nishizawa, 5-Aminolevulinic acid enhances mitochondrial stress upon ionizing irradiation exposure and increases delayed production of reactive oxygen species and cell death in glioma cells, Int. J. Mol. Med., 2017, 39, 387-398.

57 T. Chao, H. Wang and P. C. Ho, Mitochondrial Control and Guidance of Cellular Activities of T Cells, Front. Immunol., 2017, 8, 473.

58 Y. Y. Jiang, H. Huang, H. J. Wang, D. Wu, R. Yang, S. Tashiro, S. Onodera and T. Ikejima, Interruption of mitochondrial complex IV activity and cytochrome c expression activated $\mathrm{O}(2)$. (-)-Mediated cell survival in silibinin-treated human melanoma A375-S2 cells via IGF-1R-PI3K-Akt and IGF-1RPLC gamma-PKC pathways, Eur. J. Pharmacol., 2011, 668, 78-87. 